\title{
FEVER OF UNKNOWN ORIGIN
}

\author{
Maj SK DATTA ${ }^{*}$, Col MK MAHAPATRA ${ }^{+}$
}

\begin{abstract}
Forty six patients of fever of unknown origin in Service Hospitals who met the standard criteria were studied between 1989 and 1997. Infectious diseases contributed 21 patients $(45.65 \%)$ of which $13(28.26 \%)$ were diagnosed to have tuberculosis. Eight patients each $(17.39 \%)$ of malignancies and collagen vascular diseases were seen. solid tumours were found in 5 patients. One (2.17\%) patient had intrabdominal abscess. No diagnosis was made in $4(8.69 \%)$ patients. The pattern and height of fever bore no correlation to aetiology. Serially repeated radiograph of chest was the most contributory investigation giving diagnostic information in $41.3 \%$. Tissue/body fluid biopsy and cytology, serology, ultrasonography, computerised tomography and laparotomy were other useful investigations.
\end{abstract}

MJAFI 1998; 54 : 325-327

KEY WORDS: Fever of unknown origin; Pyrexia.

\section{Introduction}

$\mathbf{F}$ lever of unknown origin (FUO) is a manifestation of numerous aetiologies which vary with population, place, migration and time [1,2] studies of FUO from our country [3], other Southeast Asian [4] and developed countries [1] show significant variation in aetiology.

The aim of this study was to analyse the clinical profile, aetiology and mode of diagnosis in Service Hospitals.

\section{Method}

A total of 46 patients of classic FUO over 12 years of age were selected. All had fever as a principal symptom with temperatures of 101 degree Fahrenheit (38.3 degree centigrade) recorded on several occassions for more than 3 weeks, where diagnosis was uncertain after a week of admission and thorough investigation in hospital [1,5]. Nosocomial, neutropenic and HIV associated FUO were not included in this study [2].

Careful history with attention to chronological onset of symptoms, fever, its severity, pattern and duration was recorded. Place of residence, travel, contact with animals, preceding illness, infections, contact with tuberculosis, immunisation, drug history were noted. Serial recording of temperature was maintained. Personal recording of temperature was done at intervals to minimise factitious fever.

A weight record was maintained. Patients underwent hematological, serological, biochemical tests and cultures. A baseline chest radiograph was done in all patients. It was repented after intervals of 3-4 weeks or earlier. on appearance of localising symptoms or signs.

Biopsies of clinically suspected tissues were undertaken. Other investigations done on appearance of suggestive signs were aspiration of body fluids, immunological tests. radiograph of joints. ultrasound abdomen. $\mathrm{CT}$ scan, radioisotope imaging of kidncy. laparotomy, barium meal follow through and gastrointestinal endoscopy.
Results

A total of 46 patients were studied between July 1989 to May 1997. There were 38 males and 8 females in the study. The age range was 15 to 80 years (average 35.4 years). the average age for infections was 32.0 years, myelo- and lympho- proliferative neoplasia was 29.3 years, solid tumours 55.6 years and collagen vascular disease 34.2 years.

The average duration of fever was 3.5 months. It was the least for infections (2.6 months) and maximum for neoplasia (6.98 months). Intermittent pattern was seen in 29 patients $(63 \%)$. remittent pattern in $13(28.3 \%)$, continuous pattern in $4(8.7 \%)$. lever pattern showed no correlation with aetiology. The important clinical manifestations are outlined in Fig. I.

Thirty two (69.5\%) had weight loss of which 21 (45.6\%) patients lost more than $10 \%$ of body weight. Thirteen of 21 patients with infections had hepatosplenomegaly while 3 had only hepatomegaly. It was present in all 3 cases of leukemia. lymploma and absent in the solid tumours.

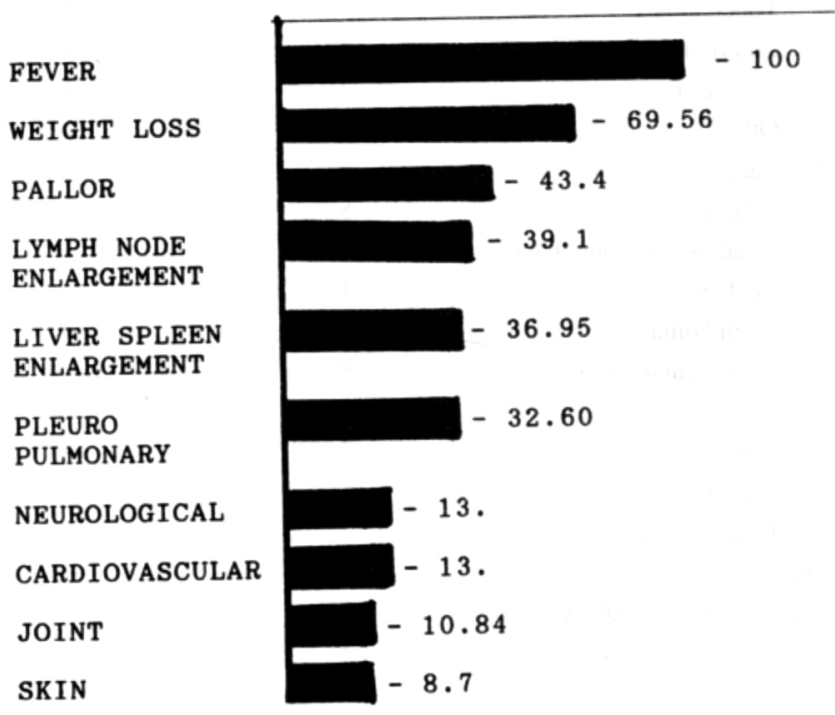

Fig. I : Clinical manifestations in FUO (\% of patients)

\footnotetext{
Graded Specialist (Medicine), Military Hospital, Trivandrum - 695006. ${ }^{\dagger}$ Senior Advisor (Medicine), Military Hospital. Jodhpur.
} 
Table 1 gives the distribution of aetiology and diagnostic investigations. Serially repeated chest radiograph was the most diagnostic investigation. It was positive in $41.3 \%$ of all patients including $11(84.61 \%)$ patients of tuberculosis. None had evidence in the base line radiograph of tuberculosis except non resolving pncumonia or apical fibrosis. Serial radiographs were also positive in $37.5 \%$ of malignancies. Biopsy of lymphnode was positive in $13.04 \%$ (tuberculosis, leukemic deposits, lymphoma and carcinoma lung); bone marrow in $8.68 \%$ (kala azar, leukemia and tuberculosis); and liver in $6.52 \%$ (lymphoma and granulomatous hepatitis). Other tissues biopsied like skin, synovium, muscle, kidney, omentum, pancreas. lung were diagnostic in $28.26 \%$ (tuberculosis. SLE, RA, vasculitis. carcinoma pancreas and carcinoma lung).Body fluid cytology was positive for inflammatory conditions but did not reveal malignancy in any case. Eosinophilia was found in a patient of vasculitis; albuminuria and urinary casts in nephritis associated with multi system disease. Serum T3, T4 TSH was diagnostic in thyrotoxicosis coexistent with tuberculosis.

Radioisolope imaging showed reduced renal uptake and delayed excretion in nephritis. CT scan (head, thorax, abdomen) was diagnostic in cerebral matastasis and tuberculoma, carcinoma pancreas and mediastinal lymphadenopathy in sarcoidosis. Laparotomy was diagnostic in carcinoma pancreas, omental and intestinal tuberculosis; barium follow through in intestinal tuberculosis, sigmoidoscopy in multi system disease (inflammatory bowel disease with polymyositis. arthritis and lieart block).

The commonest cause of FUO in this study was infection in 21 (45.65\%) patients including $13(28.26 \%)$ of tuberculosis. Six patients of tuberculosis had coexistent pathology viz. diabetes mellitus in two and one each of thyrotoxicosis. Hodgkins lymphoma, carcinoma lung. kala azar and sero negative polyarthritis. Besides kala azar and enteric fever, one patient each of salmonellosis, brucellosis with subdural hematoma and liver abseess were seen. Therapeutic trial had diagnostic value with antimycobacterials (for tuberculosis) and steroids (for SLE. RA and JRA). No diagnosis could be arrived at in 4 patients. A 50 year male with remittent fever upto 108 degree $F$, transient left sided lymphocytic pleural effusion and splenomegaly resolved spontaneously. On follow up (hemogram, serology, chest radiograph) he remained normal.

A33 year male with pallor, hepatosplenomegaly, $6 \mathrm{Kg}$ weight loss, ileus, normochromic normocytic anemia with inconclusive investigations (hematological, liver function, microbiological, biopsy of bone marrow and liver, ultrasonography abdomen, endoscopy of GIT, laparotomy) did not respond to trial of $\Lambda$ TT but gradually became afebrile over the next 3 months. A 30 year male with fever, hepatosplenomcgaly whose bone marrow cytology showed plasmacytosis, granulomatous reaction without caseation, became asymptomatic with normal marrow cytology after cmpirical treatment with antimalarials and quinolones. Another patient with generalised lymphadenopathy recovered after 1.5 months. All test including lymphnode biopsy were inconclusive. There were 4 deaths among the malignancies with one patients each of carcinoma pancreas and lung and two of acute (alcukemic) mycloblastic leukemia.

\section{Discussion}

FUO is today under review. It has been divided into 4 groups - classic, nosocomial, neutropenic and HIV associated FUO. It has also been proposed to widen the definition to fever greater than 3 weeks undiagnosed after observation over 3 out- patient visits or 3

TABLE I

Aetiology and diagnostic investigations in FUO

\begin{tabular}{|c|c|c|c|c|c|c|c|c|c|}
\hline & $\begin{array}{l}\text { No. of } \\
\text { cases }\end{array}$ & Serology & $\begin{array}{l}\text { Micro- } \\
\text { biology }\end{array}$ & $\begin{array}{l}\text { Radio- } \\
\text { graphy* }\end{array}$ & $\begin{array}{c}\text { USS } \\
\text { abdomen } \\
\text { cytology }\end{array}$ & $\begin{array}{l}\text { CTt } \\
\text { scan }\end{array}$ & $\begin{array}{c}\text { Tissue ++ } \\
\text { biopsy }\end{array}$ & $\begin{array}{l}\text { Therapcutic** } \\
\text { trial }\end{array}$ & Laparotomy \\
\hline Infections & 21 & & & & & & & & \\
\hline Tuberculosis & 13 & - & 2 & 13 & 1 & 2 & 11 & 1 & 1 \\
\hline Enteric fever & 3 & 3 & - & - & - & - & - & - & 一 \\
\hline Kala azar & 2 & - & - & - & - & - & 2 & - & - \\
\hline Others & 3 & 1 & 1 & - & 1 & 1 & - & - & - \\
\hline Malignancy & 8 & & & & & & & & \\
\hline $\begin{array}{l}\text { Solid tumour } \\
\text { (Mediastinal. lung, pancreas) }\end{array}$ & 5 & 一 & - & 2 & 1 & 3 & 3 & - & 1 \\
\hline Leukemia & 1 & - & - & - & 一 & - & 2 & - & - \\
\hline Lymphoma & 2 & - & 一 & $\mathbf{I}$ & - & - & 3 & - & - \\
\hline Collagen vascular disease & 8 & & & & & & & & \\
\hline SLE & 3 & 3 & - & 2 & 1 & 一 & 1 & 2 & - \\
\hline $\begin{array}{l}\text { Others } \\
\text { (e.g. RA. JRA) }\end{array}$ & 3 & 2 & 一 & 3 & - & 一 & 1 & 1 & - \\
\hline Unclassified & 2 & 2 & - & 1 & 1 & - & 1 & 1 & - \\
\hline Sarcoidosis & 2 & - & 一 & 2 & - & $\mathbf{i}$ & 一 & - & - \\
\hline Granulomatosis hepatitis & 2 & - & - & - & 一 & - & 2 & - & - \\
\hline Pulmonary embolism & 1 & - & - & 1 & - & 一 & - & - & - \\
\hline Unknown & 4 & - & 一 & 一 & 一 & 一 & - & 一 & 一 \\
\hline Total & 46 & 11 & 3 & 25 & 5 & 7 & 26 & 5 & 2 \\
\hline
\end{tabular}

*Chest/spinc/joints/skull/abdomen: **ATT, steroids: + Head/chestabdonen; ++Bone marrow, liver, lymphnode, skin, synovium, kidney, laparotomy tissuc. bone. Inuscle 
days in the hospital or one week of "intelligent and invasive" ambulatory investigation $[2,6]$. we opted for the criteria for classic FUO of Petersdorf [1] with observation and investigation in hospital of one week duration. It is more suitable for our patients, often coming from distant places, with variable levels of comprehension and compliance undergoing a battery of tests; for the physician in monitoring the patients, ordering timely tests (eg. blood culture and peripheral smears at height of fever), ruling out factitious fever and drug fever. Neither condition was seen in the study.

The commonest aetiology was tuberculosis in this study. All had atypical or minimal clinical radiographic findings at initial presentation and 6 had coexistent illness that confounded diagnosis. High level of awareness, availability of microbiological facilities and potent antibiotics have all but eliminated endocarditis as a cause of FUO [1]. None were seen in this study. Imaging by ultrasound and CT scan, facilitated diagnosis of intrabdominal tumours and abscesses. Laparotomy was undertaken when aetiology remained uncertain despite strong clinical, radiographic or imaged pointers to intrabdominal pathology. This is a well accepted approach to laparotomy in FUO today $[1,6]$.

Travel and migration bring illness endemic to the area of residence $[2,6]$. Kala azar was seen in this study in individuals who had resided in Bihar and Bengal. The widespread use of short courses of antimicrobial therapy for fever caused negative cultures in 3 patients of enteric fever who presented with fever, relative bradycardia, hepatosplenomegaly, neutropenia where diagnosis was delayed till significant rise was seen in Widal titres. All responded to quinolones. Widal test is known to lack correlation with clinical and immunological status. It is altered by prior antimicrobial therapy, anamnestic reaction, cross reaction with coliforms. But a 4 - fold or greater rise in titres can be given significance in diagnosis of culture negative typhoid [7].

The general term 'collagen vascular disease' is used in FUO to include conditions like SLE, RA, JRA, polymyalgia rheumatica, temporal arteritis and other multisystem disease $[6,8]$. a 80 year male with eosinophilia, nephritis, interstitial lung disease and another
38 year male with spondarthritis, polymyositis, inflammatory bowel disease, heart block and nephritis could not be classified on clinical, serological and histological pattern. They thus remained unclassified. All 4 fatalities in this study were associated with malignancies. FUO unrelated to malignancy thus has a good prognosis even if it remains undiagnosed [2,9].

Detailed clinical assessment, investigations including microbiology and chest radiography are a must, prior to labelling a patient as FUO. Repeated blood smears, buffy coat preparations, serology, culture of blood and bone marrow (cytology, aerobic and mycobacterial culture) especially in patients with hepatosplenomegaly is helpful. Bone marrow, lymphnode aspiration and biopsy were contributory in diagnosis of infections, aleukemic leukemia, lymphoma and metastatic deposits. Liver biopsy done in the absence of clues from above investigations can be productive. the positivity has been shown to be unrelated to the extent of hepatomegaly [10].

\section{REFERENCES}

1. Larsen EB, Featherstone HJ, Petersdorf RG. Fever of undermined origin : Diagnosis and follow up 105 cases. 19701980. Medicine 1982; $61: 269-93$.

2. Koneeny $P$, Davidson RN. Pyrexia of unknown origin in the 1990s: Time to redefine. J Applied Med 1997: 23 : 285-90.

3. Ganesha $A$, John L. John G. Rao $M$. Causes of prolonged fever. J Assoc Physician India 1980; $37: 41$.

4. Shoji S, Imamura A, Imai Y, et al. fever of unknown origin; a review of 80 patients from the Skin Otsu area of Japan from 1986-1992. Intern Med 1992; 33 : 74-6.

5. Brusch JL, Weinstein L. Fever of unknown origin. Med Clin N Am 1988; 72 : 1247-59.

6. Gelfand $\mathrm{J} \wedge$, Dinarello $\mathrm{CA}$. fever of unknown origin. In: Fauci, Braunwald, Isselbacher Eds. Harrisons Principles of Internal Medicine 14 Ed. new York: Mc Graw Hill, 1997; Vol I 780-85.

7. Kelkar PN, Jones E. Typhoid fever. J Assoc Physician India $1997 ; 45: 37-48$.

8. Knockaert DC, Vanneste LJ, Bobbacrs IJJ. Fever of unknown origin elderly patients. J Am Geriatr Soc 1993: 41 : 1187-92.

9. Knockaert DC. Dujardin KS. Bobbaers HJ. Long term follow up of patients with undiagnosed fever of unknown origin. Arch Intern Med 1996; 156 : 618-20.

10. Holtz T, Moseley RH, Scheiman JM. Liver biopsy in fever of unknown origin; a reappraisal. J Clin Gastroenterol 1993: 17 : 29-32 